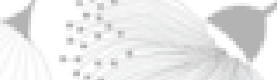

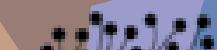

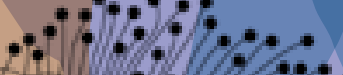

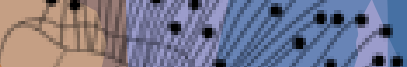
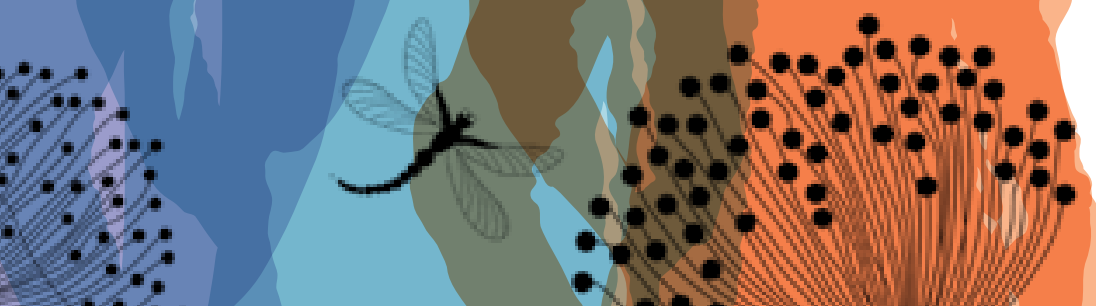

$+$,

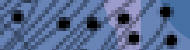

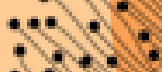

$\therefore \therefore$

.

$:$

$\because$
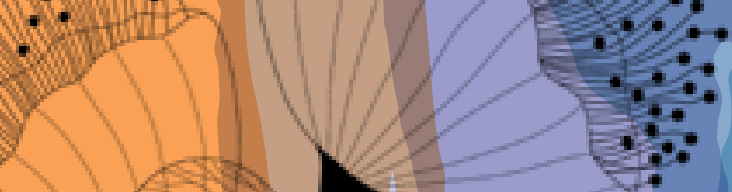

$\therefore$

$\because \%$ \%००

\title{
x.0
}

$\%$ \%० $\%$ o\%

...

$\because \because 30$ a

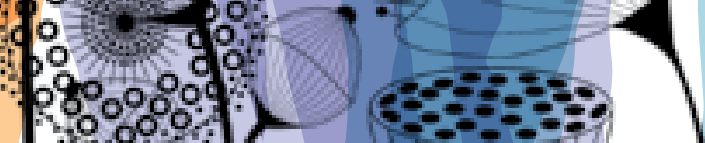
otion (5)
10

9

$101 \sqrt{9} 0$

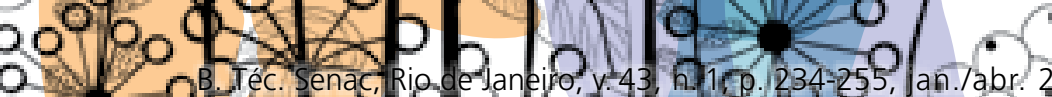
o.

960 a odoo
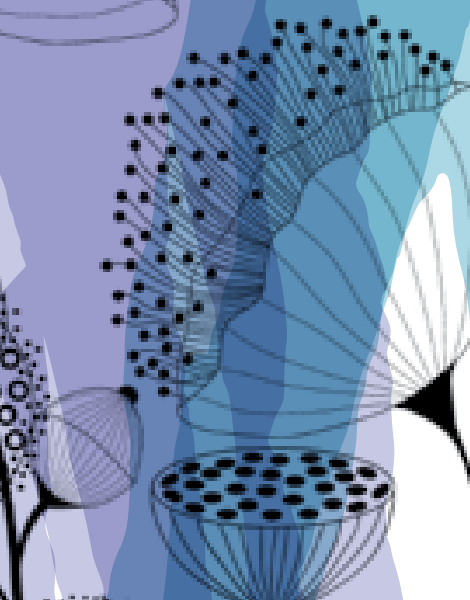

$-0$

06

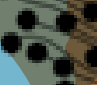
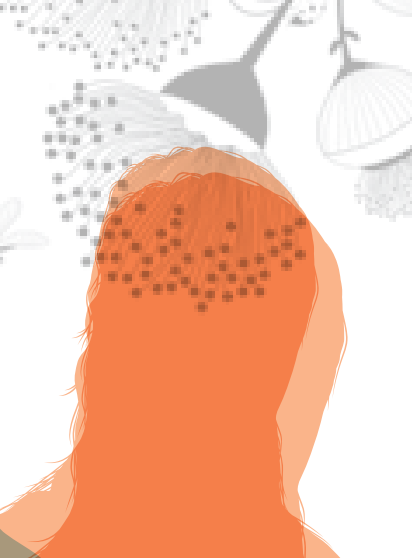
* Doutor em Educação pela Universidade Federal do Pará (UFPA). Professor Adjunto I do Departamento de Educação da Universidade Federal do Amapá (Unifap). Macapá, Amapá, Brasil. E-mail: jpaulochee@gmail. com

** Doutor em Educação pela Universidade Federal de Minas Gerais (UFMG). Professor Associado III do Instituto de Ciências da Educação (Iced) da UFPA. Belém, Pará, Brasil. E-mail: rlima@ufpa.br

Recebido para publicação em: 25.7.2016

Aprovado em: 6.2.2017

\section{ABORDAGENS SOBRE A CONDIÇÃO DE CLASSE DAS JUVENTUDES NO ESTADO DO PARÁ 1}

\section{APPROACHES ON THE CLASS CONDITION OF YOUTHS IN THE STATE OF PARÁ}

ABORDAJES SOBRE LA CONDICIÓN DE CLASE DE LOS
JÓVENES EN EL ESTADO DE PARÁ

João Paulo da Conceição Alves*

Ronaldo Marcos de Lima Araujo**

\section{Resumo}

Este artigo analisa a inserção social da(s) juventude(s) de origem trabalhadora no estado do Pará, mediante sua condição de classe. Pela análise de dados oficiais, desenvolvida a partir de pesquisa documental e bibliográfica, constatam-se altos índices de violência urbana, inserção precoce e desqualificada no mercado de trabalho e progressivo descarte da escola como alternativa capaz de promover uma formação mais humanizada a estes jovens.

Palavras-chave: Juventude. Violência. Trabalho. Educação. Classe social.

\section{Abstract}

This article analyzes the social insertion of the Pará state working youth, considering their social class. By analyzing official data, developed from documentary and bibliographic research, the study found high levels of urban violence, premature and disqualified insertion in the labor market and progressive dismissal of school as an alternative capable of promoting a more humanized training for these young individuals.

Keywords: Youth. Violence. Work. Education. Social class. 


\section{Resumen}

Este artículo analiza la inserción social de los jóvenes de origen proletario en el estado de Pará, mediante el análisis de su condición de clase. A través del análisis de datos oficiales, desarrollado a partir de la investigación documental y bibliográfica, se constatan altos índices de violencia urbana, la inserción precoz y sin calificación en el mercado de trabajo y el progresivo abandono de la escuela como alternativa capaz de promover una formación más humanizada de estos jóvenes.

Palabras clave: Jóvenes. Violencia. Trabajo. Educación. Clase social.

\section{Introdução}

O objetivo central deste trabalho é analisar a condição de classe da(s) juventude(s) no estado do Pará mediante a análise de dados oficiais. Para tanto, apresenta como problema de pesquisa: qual a condição de classe das juventudes do estado do Pará, a partir da análise de dados oficiais? Assim, discorre sobre algumas particularidades da juventude amazônida² ${ }^{2}$, refletidas em contextos marcados pelo impedimento da juventude de origem trabalhadora realizar-se nas diversas dimensões humanas (social, artística, política etc.), mediante a educação formal e suas condições de existência.

Sob uma abordagem qualitativa, utiliza-se a pesquisa documental, partindo da coleta de dados oficiais ainda não explorados e da pesquisa bibliográfica. A escolha pela investigação em dados oficiais se justifica no sentido desta análise cumprir a função de contribuir para a caracterização da(s) juventude(s) no estado do Pará.

Na pesquisa documental, o trabalho do(a) pesquisador(a) requer uma análise mais cuidadosa, visto que os documentos não passaram antes por nenhum tratamento científico (OLIVEIRA, 2007).

Lüdke e André (1986) falam sobre a importância do uso de documentos em investigações educacionais, realizando as seguintes indagações: “Que é análise documental? Quais as vantagens do uso de documentos em pesquisa? Quando é apropriado o uso dessa técnica? ". Apresentando-se como técnica exploratória, a análise documental indica problemas que devem ser melhor estudados por meio de outros métodos.

Para análise dos dados coletados, utilizou-se a análise de conteúdo. Trata-se de uma entre distintas formas de interpretar o conteúdo de um texto, adotando normas sistemáticas de extrair significados temáticos ou os signi- 
ficantes lexicais por meio dos elementos mais simples do texto. Pressupõe, assim, que um texto contém sentidos e significados, patentes ou ocultos, que podem ser apreendidos por um leitor que interpreta a mensagem contida nele por meio de técnicas sistemáticas apropriadas. A mensagem pode ser apreendida, decompondo-se o conteúdo do documento em fragmentos mais simples, que revelem sutilezas contidas em um texto. Os fragmentos podem ser palavras, termos ou frases significativas de uma mensagem $(\mathrm{CHI}-$ ZZOTTI, 2006).

Com o intuito de contribuir para a utilização da análise documental em pesquisa, apresenta-se o processo de investigação no qual são descritos os instrumentos e meios de realização da análise de conteúdo, apontando o percurso em que as decisões foram sendo tomadas quanto às técnicas de manuseio de documentos: desde a organização e classificação do material até a elaboração das categorias de análise (PIMENTEL, 2001).

O presente trabalho trata de "juventudes", já que há muitas peculiaridades para o ser jovem em um estado amazônico marcado por contrastes sociais diversos. Entretanto, não se abandona o conceito de classes sociais (para não cair no atomismo), já que as diferentes juventudes sofrem diferentemente os impactos da sociabilidade do capital, em particular, os jovens de origem trabalhadora.

Dayrell e Gomes (1999) conceituam juventude como, ao mesmo tempo, uma condição social e um tipo de representação. De um lado, há um caráter universal, dado pelas transformações do indivíduo em determinada faixa etária. De outro, há diferentes construções históricas e sociais relacionadas a esse tempo/ciclo da vida. Em linhas gerais, pode-se dizer que a entrada na juventude se faz pela adolescência e é marcada por transformações biológicas, psicológicas e de inserção social.

Compreendendo que a juventude se constitui como construção histórica e social, o que impõe reconhecer a existência de "juventudes". Entende-se, portanto, "juventudes como unidade do diverso econômico, cultural, étniCo, de gênero, de religião etc." (FRIGOTTO, 2004).

Este trabalho compreende o conceito de juventudes como complexidade variável, que se distingue por suas muitas maneiras de existir nos diferentes tempos e espaços sociais. Os jovens na sociedade não constituem uma classe social ou grupo homogêneo, como muitas análises permitem intuir. Os jovens compõem agregados sociais com características continuamente flutuantes. As idealizações políticas que procuram unificar os sentidos dos movimentos sociais da juventude tendem a ser ultrapassadas pelo contínuo movimento da realidade (CARRANO, 2007). 
Considera-se, portanto, "juventudes amazônidas" sob uma condição diversa, que leva em conta as singularidades étnicas, biológicas e de gênero. Ao mesmo tempo, aponta-se que a dimensão de classe social tem centralidade nesta construção histórica, pois os jovens de origem trabalhadora constituem grupo submetido a condições de maior precariedade social, em distinção aos jovens das classes dominantes. Assim, não é a condição étnica que define a vida da juventude amazônida, mas principalmente, a sua condição de classe.

O trabalho está organizado em seções que buscam caracterizar o perfil da(s) juventude(s) paraense(s), para em seguida, analisar as categorias: Juventude Urbana E Violência; Juventude Paraense: Trabalho/Emprego e Rendimentos; e Juventude Paraense e Educação.

De uma forma geral, as singularidades das juventudes no estado do Pará relacionam-se com a realidade de uma região periférica de um país de capitalismo também periférico, o que impõe, portanto, que os problemas levantados requerem soluções urgentes, que enfrentem aspectos estruturais e também conjunturais da realidade social da região amazônica.

\section{Perfil quantitativo da juventude na Amazônia paraense}

A Amazônia, na sua totalidade, "contempla uma complexa sociobiodiversidade que se materializa nas matas, caudalosos rios, diversificadas fauna e flora, natureza essa que abriga uma multiplicidade de populações, culturas e tradições" e identidades juvenis, que contribuem na definição do perfil dessa população (FREIRE, 2007).

Ao considerar a importância e abrangência desta totalidade da Amazônia paraense, esta pesquisa propõe o recorte da realidade da juventude paraense como expressão da realidade amazônica.

Desta maneira, na definição do perfil dos jovens na Amazônia paraense, observa-se que o estado do Pará possui uma população de 7.581.051, sendo 2.243.780 com a faixa etária de 15 a 29 anos. Desta população de 15 a 29 anos, $1.566 .371,(69 \%)$, residem na zona urbana e $677.409,(31 \%)$, residem na zona rural. Ao defini-la conforme o sexo, da população total de jovens de 15 a 29 anos, 1.125 .354 são homens e 1.118 .426 são mulheres (ARAÚJO, 2013).

Considerando a definição do perfil da população paraense sob o critério racial, a Tabela 1 apresenta o perfil da população jovem paraense:

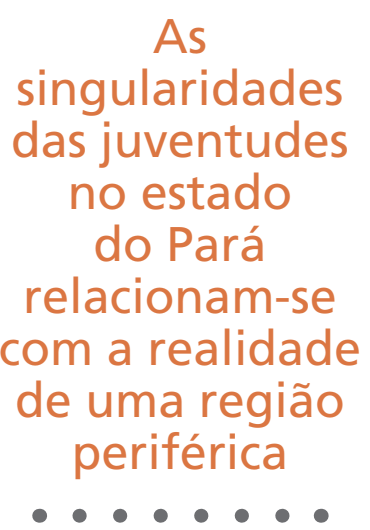

das juventudes

no estado do Pará

relacionam-se

com a realidade

e uma regiáo 
Tabela 1 - População jovem de 15 a 29 anos, segundo etnia no estado do Pará, 2010

\begin{tabular}{c|c|c}
\hline Etnia $^{\mathbf{3}}$ & $\mathbf{N}$ & $\mathbf{\%}$ \\
\hline Branca & 508.498 & 22,6 \\
Preta & 283.823 & 12,6 \\
Amarela & 23.403 & 1 \\
Parda & 1.410 .050 & 64 \\
Indígena & 17.783 & 0,8 \\
Sem declaração & 223 & 0,1 \\
\hline Total & $\mathbf{2 . 2 4 3 . 7 8 0}$ & $\mathbf{1 0 0}$ \\
\hline
\end{tabular}

Fonte: Araújo (2013).

Neste sentido, observa-se que ampla maioria desta população é constituída por jovens "negros", de acordo com classificação de Osorio (2003) na qual a caracterização trata-se da soma de pretos e pardos -, desapontando algumas classificações apressadas que informam uma população entre brancos e negros quantitativamente equilibrada. Outro elemento importante diz respeito ao reduzido número de jovens paraenses que se autodeclaram indígenas, negando a identidade cultural da sociedade amazônica, ainda que os dados sejam significativos em comparação às demais regiões do país.

O perfil do jovem amazônida, entretanto, não pode ser homogeneizado em um quadro eminentemente urbano-cêntrico, ou mesmo que requeira um ou outro perfil definido. Mas deve-se considerar as diversas especificidades e classificações deste jovem na região.

Considerando a multiplicidade de elementos que buscam definir o perfil do jovem amazônida, considera-se, ainda, a existência de várias juventudes rurais. Define-se como

Povos das águas, das florestas e dos campos amazônicos - ribeirinhos, extrativistas, seringueiros, indígenas, quilombolas, assentados da reforma agrária, pescadores, agricultores familiares etc. - e afirmam sua identidade reproduzindo historicamente seu modo de vida, de produzir e existir sociocultural e ambientalmente (FREIRE, 2007).

Tratam-se de "diversas juventudes", marcadas por peculiaridades e nuanças distintas, as quais apontam, por exemplo, que cerca de 70\% (315.000) da população indígena do Brasil está situada na Amazônia legal, distribuída em 562 terras indígenas. Essa população é predominantemente jovem e cresce em proporção de 3,5\% ao ano (MUSEU..., 2010).

Em outra categoria, dados oficiais revelam que, no Brasil, há em torno de 2.849 comunidades quilombolas, sendo que 2.401 estão certificadas. O estado do Pará concentra cerca de 245 dessas comunidades, todavia, 188 
comunidades são certificadas pela Fundação Palmares. O número é expressivo, considerando que corresponde a cerca de $8,59 \%$ (245) da população quilombola nacional (2.849).

A forte presença de movimentos sociais, particularmente do Movimento Sem Terra, contribui na definição do(s) perfi(s) do jovem amazônida. Nessa perspectiva, a população jovem presente nos assentamentos rurais constitui parte integrante na definição do perfil dessa juventude. Um dos depoimentos de uma jovem de um assentamento da reforma agrária contribui nessa direção:

Eu vivo a minha juventude no campo, pois me orgulho de ser uma colona. Não tenho vergonha de minha cultura, eu sou uma mulher que trabalha no campo. Na minha juventude, estou lutando por um futuro, o de conseguir muitas coisas para minha comunidade. Eu me sinto privilegiada em morar no campo, por nossas culturas, nossos jeitos de ser (Jovem assentada da reforma agrária, Aveiro/Pará/Brasil apud FREIRE, 2007).

Afirma-se, para efeito comparativo entre a realidade regional e nacional, que $65 \%$ da população jovem na Amazônia está nas zonas urbanas, contra 78\% do restante do Brasil.

Ainda como grupo que compõe o quadro de jovens da Amazônia, pode-se apontar nessa composição os jovens das periferias urbanas. Chama atenção no teor desses dados seu caráter social. Admite-se, por exemplo, que a maioria desses jovens urbanos se concentram em bolsões de pobreza onde convivem cotidianamente com a indignidade das condições de moradia e violência.

Dados oficiais, por exemplo, revelam que a moradia de jovens residentes em zonas urbanas das cidades amazônicas apresenta condições deploráveis. Um exemplo bastante ilustrativo refere-se ao fato de cerca de $40 \%$ dos jovens residirem em aglomerados subnormais ${ }^{4}$. A Tabela 2 confirma a assertiva feita:

Tabela 2 - Condição de moradia de jovens de 15 a 29 anos, alfabetizados, residentes em domicílios particulares ocupados no estado do Pará, 2010

\begin{tabular}{c|c|c}
\hline $\begin{array}{c}\text { Pessoas alfabetizadas residentes em domicílios particulares } \\
\text { ocupados - 15 a } \mathbf{2 9} \text { anos }-\mathbf{2 0 1 2}\end{array}$ & N. & $\%$ \\
\hline $\begin{array}{c}\text { Jovens residentes em AGLOMERADOS SUBNORMAIS }{ }^{5} \text { (favelas, } \\
\text { invasões, grotas, baixadas, comunidades, vilas, ressacas, mocambos, } \\
\text { palafitas, entre outros) }\end{array}$ & 373.880 & 40,4 \\
\hline $\begin{array}{c}\text { Jovens residentes na zona URBANA } \\
\text { Jovens residentes na zona RURAL }\end{array}$ & 455.229 & 49,2 \\
\hline Total & 96.704 & 10,4 \\
\hline
\end{tabular}

Fonte: Araújo (2013).

B. Téc. Senac, Rio de Janeiro, v. 43, n. 1, p. 234-255, jan./abr. 2017. 
Estes dados adquirem uma faceta ainda mais alarmante quando analisados sob o prisma étnico-racial. O Instituto Brasileiro de Geografia e Estatística (IBGE) revela que entre os moradores dos aglomerados subnormais 21\% são brancos (na zona urbana os brancos somam 28\%) e $77 \%$ são pretos ou pardos.

\section{Juventude urbana e violência no estado do Pará}

Um conjunto de informações e dados oficiais sobre a juventude e violência urbana são apresentados sob um quadro geral, mas bastante desafiador, por trazer à tona o processo de barbárie a que está submetida a juventude paraense.

Trata-se de refletir sobre o processo de (des)humanização dessa juventude, demonstrando que a questão de classe social, aliada a outros elementos, como a violência (e ainda outras variáveis, especificamente relacionadas a etnia, idade e gênero), constroem um perfil de jovem mutilado de suas necessidades básicas.

Dados de Cerqueira (2016) sobre a classificação dos estados da Federação segundo as taxas de homicídio juvenil apontam o Pará, com 77,9 homicídios a cada 100 mil jovens, como o sexto estado da Federação com maior número de homicídios. Nessa mesma pesquisa, a média nacional ficou em 57,3 homicídios a cada 100 mil jovens, representando uma diferença de 20 homicídios a mais que os dados do estado do Pará.

humanização dessa juventude

A Tabela 3 aponta o quadro geral de homicídios em estados da região Norte e no Brasil como um todo, por faixa etária de 15 a 29 anos:

Tabela 3 - Número de homicídios em estados da região Norte e Brasil por faixa etária de 15-29 anos de idade no período de 2011 a 2014 e com variações de períodos distintos

\begin{tabular}{c|c|c|c|c|c|c}
\hline $\begin{array}{c}\text { Unidades da } \\
\text { Federação }\end{array}$ & $\mathbf{2 0 1 1}$ & $\mathbf{2 0 1 2}$ & $\mathbf{2 0 1 3}$ & $\mathbf{2 0 1 4}$ & $\begin{array}{c}\text { Variação de } \\
\mathbf{2 0 1 3} \mathbf{a} \mathbf{2 0 1 4}\end{array}$ & $\begin{array}{c}\text { Variação de } \\
\mathbf{2 0 0 4} \text { a 2014 }\end{array}$ \\
\hline Acre & 74 & 102 & 124 & 112 & $-9,7 \%$ & $49,3 \%$ \\
Amapá & 121 & 164 & 142 & 155 & 9,2 & $31,4 \%$ \\
Amazonas & 791 & 728 & 655 & 673 & $2,7 \%$ & $118,5 \%$ \\
Pará & $\mathbf{1 7 5 6}$ & $\mathbf{1 8 0 3}$ & $\mathbf{1 8 0 1}$ & $\mathbf{1 8 1 5}$ & $\mathbf{0 , 8} \%$ & $\mathbf{1 2 2 , 7 \%}$ \\
Rondônia & 187 & 228 & 209 & 217 & $3,8 \%$ & $-21,9 \%$ \\
Roraima & 39 & 69 & 79 & 57 & $-27,8 \%$ & $32,6 \%$ \\
Tocantins & 160 & 177 & 148 & 176 & $18,9 \%$ & $70,9 \%$ \\
\hline Brasil & $\mathbf{2 7 . 4 7 1}$ & $\mathbf{3 0 . 0 7 2}$ & $\mathbf{3 0 . 2 1 3}$ & $\mathbf{3 1 . 4 1 9}$ & $\mathbf{4 , 0 \%}$ & $\mathbf{1 6 , 4 \%}$ \\
\hline
\end{tabular}

Fonte: Atlas da Violência (CERQUEIRA, 2016). 
Neste caso, observa-se os dados oficiais sobre os índices de homicídios no estado, primeiramente, comparando-os com a realidade nacional, a qual permite afirmar que são altas as taxas relacionadas ao número de homicídios no estado do Pará, visto que, por exemplo, enquanto no Brasil, na variação dos anos de 2004 e 2014, registrou-se um aumento 16,4\%, no estado do Pará, esse índice foi de $122 \%$, representando um índice mais de sete vezes maior que a média nacional.

Se comparado aos demais estados da região Norte, o Pará apresenta o pior dos índices de crescimento no período de 2004 a 2014, mesmo considerando que, nos últimos anos, os índices têm crescido, no entanto de uma forma mais contida, a exemplo do período de 2013 e 2014, quando a taxa de aumento ficou em torno de $0,8 \%$.

Na análise dos índices de violência em Belém (PA), os dados revelam que os jovens residentes nas periferias dos centros urbanos constituem-se as maiores vítimas da violência. Dados sobre a juventude na capital paraense apontam que 89\% dos óbitos, entre 15 e 19 anos, foram por causas violentas, principalmente por homicídio (ARAUJO, 2007).

Dados coletados junto ao Hospital Pronto Socorro Municipal de Belém Mário Pinotti, ao Hospital Pronto Socorro do Guamá, Hospital de Urgência e Emergência Dr. Augusto Chaves, localizado no bairro de Marituba e ao Centro de Perícias Científicas Renato Chaves apontam que, no período compreendido entre 2000 e 2006, a violência urbana afetou majoritariamente jovens entre 17 a 27 anos (ARAUJO, 2007).

No caso específico das três primeiras unidades de saúde, os atendimentos realizados em decorrência de agressão física, arma de fogo, arma branca, acidente de trânsito e tentativa de homicídio revelam que a violência urbana, no Pará e particularmente em Belém, tem sexo, idade e etnia, ou seja, $60 \%$ são homens jovens pardos ou negros.

Araujo (2007), em pesquisa concluída no ano de 2007, sob o tema “Diagnóstico dos Direitos Humanos no estado do Pará" revela que o quadro se agrava quando se examinam as mortes por causas violentas. A consulta realizada em 919 prontuários de cadáveres masculinos, de 2006, no Instituto de Polícia Científica Renato Chaves, justifica a preocupação.

De uma forma geral, a tabela nos revela que $65,2 \%$ das vítimas por causa violenta estão na faixa etária entre 17 e 29 anos. Os dados também indicam que a situação é similar na Região Metropolitana de Belém, onde é possível inferir que, mensalmente, morria, em 2007, mais de 100 jovens por causa violenta, correspondendo a valor extremamente preocupante para uma etapa de idade que teoricamente expressa uma vida mais saudável e produtiva. 
A violência

e suas

consequências

fatais afetam mais os jovens
Esta realidade reitera uma tendência nacional, que tem apontado para o fato de que a violência e suas consequências fatais afetam mais os jovens, como afirma Fernandes (2004) ao estudar os dados no Rio de Janeiro. Isso permite refletir que as fronteiras entre as grandes metrópoles e as pequenas e médias cidades deixaram de existir quando se trata da sociabilidade contemporânea que banaliza a vida.

\section{Juventude paraense: trabalho/emprego e rendimentos}

O tratamento da juventude paraense refere-se, neste trabalho, à classificação adotada pelo Estatuto da Juventude (Lei n. 12.852, de 5 de agosto de 2013), a qual considera como jovens os sujeitos na faixa etária de 15 a 29 anos $^{6}$.

No tratamento desta dimensão da vida juvenil, tem-se um quadro bastante problemático. Os elementos de ordem econômica relacionados a rendimentos conferem grande importância nesta análise por estarem principalmente imbricados com a qualidade de vida da população jovem na Amazônia. A Tabela 4 revela o percentual de jovens ocupados por classes de rendimento mensal dos trabalhos, a partir dos estados da região Norte e Brasil.

Tabela 4 - Jovens de 15 a 29 anos de idade, ocupados na semana de referência, por classes de rendimento mensal de todos os trabalhos, segundo estados da região Norte e do Brasil, 2012

\begin{tabular}{c|c|c|c|c}
\hline \multirow{2}{*}{$\begin{array}{c}\text { Brasil, Região Norte } \\
\text { e Estados e Região }\end{array}$} & \multicolumn{4}{|c}{$\begin{array}{c}\text { Distribuição percentual de jovens de 15 a 29 anos por } \\
\text { classes de rendimento mensal de todos os trabalhos (\%) }\end{array}$} \\
\cline { 2 - 5 } $\begin{array}{c}\text { Metropolitana de Belém } \\
\text { Até 1/2 } \\
\text { salário } \\
\text { mínimo }\end{array}$ & $\begin{array}{c}\text { Mais de 1/2 } \\
\text { a 1 salário } \\
\text { mínimo }\end{array}$ & $\begin{array}{c}\text { Mais de 1 } \\
\text { a 2 salários } \\
\text { mínimos }\end{array}$ & $\begin{array}{c}\text { Mais de } \\
\text { 2 salários } \\
\text { mínimos }\end{array}$ \\
\hline Brasil & $\mathbf{1 5 , 7}$ & $\mathbf{2 3 , 9}$ & $\mathbf{3 9 , 9}$ & $\mathbf{1 8 , 2}$ \\
Norte & 26,4 & 31,0 & 30,4 & 11,0 \\
Rondônia & 20,4 & 25,2 & 36,7 & 16,7 \\
Acre & 32,8 & 26,4 & 28,0 & 11,9 \\
Amazonas & 23,8 & 30,8 & 31,6 & 12,3 \\
Roraima & 15,0 & 36,4 & 32,2 & 16,0 \\
Pará & $\mathbf{3 0 , 4}$ & $\mathbf{3 2 , 2}$ & $\mathbf{2 7 , 6}$ & $\mathbf{8 , 2}$ \\
Região Metropolitana & $\mathbf{9 , 6}$ & $\mathbf{3 8 , 3}$ & $\mathbf{3 4 , 2}$ & $\mathbf{1 1 , 5}$ \\
de Belém (RMB) & & & & 14,5 \\
Amapá & 9,9 & 32,2 & 43,3 & 11,7 \\
\hline Tocantins & 24,1 & 32,8 & 30,7 & \\
\hline
\end{tabular}

Fonte: IBGE (2012). 
Considerando a ideia de inserção da juventude paraense no mercado de trabalho de maneira qualificada, dados do IBGE (PNAD) revelam que ela se dá de forma precária, precoce e desqualificada. Observa-se que o estado do Pará apresenta o segundo maior índice de jovens que possuem rendimento mensal de até $1 / 2$ salário mínimo, representado praticamente o dobro do índice nacional. Além disso, cerca de 47,9\% $38 \%+9,6 \%=$ $47,9 \%$ ), ou quase a metade dos jovens da RMB, possuem rendimentos de até um salário mínimo.

Por outro lado, ao analisar os maiores rendimentos dos jovens de 15 a 29 anos, tanto o estado do Pará como a RMB apresentam os menores percentuais. O Pará apresenta o pior índice, com apenas 8,6\% dos jovens com rendimentos superiores a dois salários mínimos. E a RMB apresenta um dos mais baixos percentuais, neste caso, superior apenas em comparação ao próprio estado do Pará, que dele faz parte.

Portanto, os jovens paraenses assumem em muitos casos como única perspectiva a inserção no mercado de trabalho precocemente como estratégia necessária para sua sobrevivência. Os dados confirmam o contexto da inserção da juventude paraense no mercado de trabalho, marcada por uma inclusão precoce, desqualificada e com baixos rendimentos.

A análise, neste momento, não se restringe a dizer que os jovens paraenses ocupados possuem baixa remuneração no mercado de trabalho, mas significa, acima de tudo, que esses rendimentos constituem expressão de desqualificação profissional sob a marca da pobreza e da exclusão social.

Gentilli (2009) destaca que o problema da exclusão e da pobreza é estrutural, no qual três fatores contribuem para produzir a universalização sem direitos e a expansão da educação de forma regulada. São eles: a) a combinação e articulação de condições de pobreza e desigualdade vividas por um significativo número de pessoas em nossas sociedades; b) o desenvolvimento fragmentado dos sistemas escolares e os enormes diferenciais de oportunidades que as escolas oferecem e c) a promoção de uma cultura política sobre os direitos humanos - e particularmente sobre o direito à educação - marcada por uma concepção privatista e economicista que, longe de ampliar, restringe as fronteiras desse direito às oportunidades de acesso e permanência no mercado de trabalho.

Portanto, se por um lado a juventude paraense precisa trabalhar precocemente e recebe por isso rendimentos precários, por outro, sua escolarização não favorece a inserção mais qualificada. 
Assim, a educação da juventude tanto no estado do Pará como na sua capital, Belém, se revela pouco promissora para a formação dos jovens em suas múltiplas potencialidades e principalmente para sua humanização.

A negação da educação a quem é de direito pode se materializar na qualidade da escola e no rendimento dos jovens. Esta situação pode ser revelada nas taxas de aprovação, reprovação e abandono dos alunos no ensino médio no Pará, conforme a Tabela 5, apresentada a seguir:

Tabela 5 - Taxa de rendimento no Nível Médio, segundo localização, na rede pública de ensino, no município de Belém, Região Norte, estado do Pará e Brasil, em 2015

\begin{tabular}{c|c|c|c|c}
\hline Abrangência & Localização & Aprovação & Reprovação & Abandono \\
\hline Brasil & Total & 79,8 & 12,4 & 7,8 \\
Norte & Total & 75,7 & 10,2 & 14,1 \\
Pará & Total & $\mathbf{7 0 , 4}$ & $\mathbf{1 1 , 0}$ & $\mathbf{1 8 , 6}$ \\
Pará & Urbana & 70,4 & 11,1 & 18,5 \\
Pará & Rural & 71,3 & 9,4 & 19,3 \\
Belém & Total & $\mathbf{6 7 , 7}$ & $\mathbf{1 5 , 5}$ & $\mathbf{1 6 , 8}$ \\
\hline
\end{tabular}

Fonte: INEP (2015b).

Os dados sobre rendimento escolar demonstram que o estado do Pará, nas zonas urbana e rural, apresenta os piores índices de desempenho em comparação aos índices da região Norte e ao próprio Brasil. A capital paraense, Belém, por sua vez, apresenta os piores índices de rendimento de alunos no ensino médio. O número de alunos belenenses aprovados em 2015, por exemplo, é inferior às médias nacionais e regionais, incluindo a zona rural do estado do Pará.

A situação é grave, pois se os números nacionais e regionais já apontam para a busca de metas para uma melhor qualidade do ensino médio, o estado do Pará e particularmente a cidade de Belém expõem essa problemática de forma mais profunda.

Por isso, pode-se afirmar que a educação da juventude paraense pobre se apresenta sob o risco do presente e com o futuro da maioria de seus jovens ameaçado. Além disso, há de se notar que o acesso à escola não garante, por si, uma educação de boa qualidade, visto que as escolas apresentam um projeto de educação dual e desigual, reforçando o antagonismo de classes.

Percebe-se, de forma geral, que a situação da juventude no Pará torna-se uma problemática ao se analisar que os jovens que trabalham apresentam uma inserção precoce e com pouca qualificação no mercado, decorrente de uma escolarização insipiente, expondo as fissuras e um drama nessa fase de definição e autoafirmação em suas vidas. 


\section{Juventude paraense e educação}

De acordo com o Araújo (2013), o estado do Pará tem uma população de 6.062.304 habitantes com mais de dez anos de idade e destes há 1.030.589 (17\%) que nunca frequentaram a escola e 759.589 analfabetos. Estes números revelam o quão longe ainda está uma democracia efetiva, capaz de assegurar, pelo menos, a equidade de condições educacionais para a população brasileira.

Considerando apenas a população adulta (com mais de 18 anos), que totaliza mais de 4,5 milhões de paraenses, apenas 1.146 .771 pessoas (25\%) têm o ensino médio completo. Além disso, as taxas de escolarização revelam a vulnerabilidade da juventude paraense, conforme tabela a seguir:

\section{Tabela 6 - Taxas de escolarização de jovens no estado do Pará, 2010}

\begin{tabular}{c|c|c|c|c}
\hline Faixa etária & $\begin{array}{c}\text { População } \\
\text { residente }\end{array}$ & $\begin{array}{c}\text { Frequentavam } \\
\text { a escola }\end{array}$ & $\begin{array}{c}\text { Taxa bruta de } \\
\text { escolarização }\end{array}$ & $\begin{array}{c}\text { Taxa líquida de } \\
\text { escolarização }\end{array}$ \\
\hline 15 a 17 anos & 486.649 & 396.698 & $81,5 \%$ & 37,3 \\
18 ou 19 anos & 300.753 & 153.973 & $51 \%$ & 7,4 \\
20 a 24 anos & 749.055 & 185.381 & $24,7 \%$ & 11,3 \\
25 anos ou mais & 3.689 .490 & 283.557 & $7,6 \%$ & 3,47 \\
\hline
\end{tabular}

Fonte: Conselho Estadual de Educação (2013).

De acordo com a tabela acima, o estado do Pará tinha 486.649 jovens na idade entre 15 e 17 anos, no entanto, destes, apenas 396.698 frequentavam escola, ou seja, 89.951. Neste caso, aproximadamente $20 \%$ dos jovens estavam fora da escola. Tal situação se apresenta ainda mais preocupante quando se observa que apenas 100 mil dessas matrículas eram de jovens na faixa etária recomendada (15 a 17 anos).

O ensino médio é a etapa conclusiva da educação básica, a qual deve assegurar o acesso ao patrimônio cultural que permitirá aos jovens entrar na vida adulta com uma condição social digna, como informa Kuenzer (2007) ao destacar também que o ensino médio é direito de todos os adolescentes, independentemente de sua origem de classe. Do mesmo modo, enfatiza-se que a escola pública possui importante papel na construção de uma proposta pedagógica que propicie situações de aprendizagem socioculturais significativas para os estudantes. 
No entanto, os números mencionados mostram um claro indicativo de que a maioria da juventude paraense tem seu futuro ameaçado. São perto de 100 mil jovens entre 15 e 17 anos fora da escola e mais 290 mil atrasados em

Ficam mais fora da escola ou atrasados os jovens oriundos das classes trabalhadoras

$\bullet \bullet \bullet$ relação à série recomendada.

Apenas perto de 100 mil jovens entre 15 e 17 anos estão onde deveriam estar, matriculados em uma escola de ensino médio. Não é preciso nenhum profundo estudo sociológico para afirmar que entre esses jovens prevalecem aqueles oriundos das camadas econômicas mais altas. Ficam mais fora da escola ou atrasados os jovens oriundos das classes trabalhadoras.

O ensino médio tem a função social, portanto, de consolidar uma formação que se iniciou na pré-escola e no ensino fundamental, a qual deveria servir para que todo cidadão conseguisse se comunicar com clareza (para isso estuda português), pensar logicamente (para isso estuda matemática), situar-se no seu tempo e no seu espaço (para isso serve o estudo da história e da geografia), compreender os fenômenos físicos, químicos, biológicos, sociais de modo a ter as ferramentas para decidir autonomamente sobre os rumos de sua vida e colaborar para a organização da comunidade na qual está inserido.

A escola pública por sua vez, é uma das poucas possibilidades de a juventude trabalhadora construir uma vida mais digna. Neste caso, destacamos a rede estadual por concentrar a maioria das matrículas no ensino médio no Pará. A Tabela 8 mostra o número total de matrículas no ensino médio por dependência administrativa no estado do Pará, no período de 2008 a 2012.

\section{Tabela 7 - Número de matrículas no ensino médio, normal/ magistério e integrado por dependência administrativa, no estado do Pará - 2008 a 2012}

\begin{tabular}{c|c|c|c|c|c}
\hline Ano & Total & Federal & Estadual & Municipal & Privada \\
\hline 2008 & 337.815 & 2.900 & 309.963 & 369 & 24.583 \\
2009 & 346.796 & 2.963 & 319.469 & 269 & 24.095 \\
2010 & 356.885 & 3.421 & 325.604 & 299 & 27.561 \\
2011 & 352.602 & 3.682 & 318.094 & 296 & 30.530 \\
2012 & 356.554 & 3.819 & 319.180 & 187 & 33.368 \\
\hline
\end{tabular}

Fonte: Conselho Estadual de Educação (2013).

Entre as análises que podem ser feitas a partir da Tabela 7, ressalta-se que o período de 2008 a 2012 revelou que a rede estadual de ensino obteve um tímido crescimento absoluto nas matrículas, distintamente da rede privada, que, apesar de possuir uma rede de ensino quantitativamente inferior, obteve crescimento considerável. Neste caso, observa-se que a criação de vagas no ensino médio não tem acompanhado os índices de crescimento da população paraense. 
Negar o acesso ao ensino médio para os jovens significa negar-lhes as ferramentas culturais básicas que favorecem uma vida adulta digna e colocar-lhes em situação de vulnerabilidade social e econômica, colocando em risco, também, o futuro da sociedade em que estão inseridos.

Em contraposição à realidade da escola vivida no ensino médio, Ciavatta e Ramos (2011) destacam a necessidade de integração do trabalho, da ciência e da cultura no processo formativo dos sujeitos. Vislumbram uma escola única e que tenha como horizonte a formação politécnica e omnilateral dos trabalhadores, com o propósito de compreender as relações sociais de produção e do processo histórico e contraditório de desenvolvimento das forças produtivas.

De forma geral, os indicadores de qualidade da educação amazônica são baixos comparativamente às demais regiões. O Pará, em particular, tem o mais baixo Índice de Desenvolvimento da Educação Básica (IDEB) de ensino médio de toda a região norte $(3,0)$, e o $22^{\circ}$ pior IDEB do Brasil, em particular, um dos mais baixos índices do ensino médio entre todas as redes estaduais de ensino (INEP, 2015a).

Tão grave quanto esses resultados é o fato de que eles estão piorando. No geral, aprova-se pouco e cada vez menos. Aprende-se pouco e cada vez menos. Os resultados do IDEB, mais que números, revelam que a juventude paraense tem seu presente prejudicado e o seu futuro ameaçado.

Dados do INEP (2013) apontam que, no Brasil, das pessoas que se encontram na faixa etária entre 15 a 24 anos (o que equivale a cerca de $20 \%$ da população do país), cerca de $50 \%$ está fora da escola. Essa problemática é evidenciada principalmente entre brancos pobres, índios, negros e seus descendentes, particularmente, os residentes na região Norte.

Como forma de aprofundar essa análise, Araujo (2007) analisa que, se for considerado o número total de matrículas no ensino médio paraense, será verificado um déficit de 84.960 vagas; e se for observada a faixa etária indicada para o ensino médio, esse déficit é de 346 mil vagas, o que revela uma grande defasagem tanto no ensino fundamental quanto no ensino médio.

Mas quais seriam as causas desse grave quadro? Elas precisariam ser bem estudadas, mas, de antemão, não se pode identificar uma única causa para essa situação e há que se discordar de qualquer tentativa de responsabilizar os professores pela má qualidade da aprendizagem: eles fazem mais parte da solução do que do problema.

Há uma hipótese de que essa situação pode ser entendida em função dos modelos entreguistas de desenvolvimento da região e da falta de compromisso 
das elites com a boa formação de seu povo. Tem-se uma elite que convive bem com diferentes mazelas que afligem os paraenses: trabalho escravo, pedofilia, falta de saneamento, grande concentração de terras e riquezas, assassinatos de trabalhadores e lideranças políticas, corrupção generalizada, precariedade da saúde pública etc.

O desenvolvimento da região sempre foi dependente, o que tinha de meIhor nunca ficou para o povo trabalhador, vide os ciclos da borracha, dos grandes projetos, da indústria de mineração e da agroindústria: quem ganhou e quem ganha com eles? Não é e nem foi o trabalhador.

Parte do problema também pode ser explicado pelos baixos investimentos na educação. Enquanto o gasto médio de um estudante de ensino médio, nos países da Organização para a Cooperação e Desenvolvimento Econômico (OCDE), é de perto de 10 mil dólares, no Brasil, este custo fica em torno de 2,5 mil. No Pará, é de aproximadamente 1,5 mil dólares (ORGANIZAÇÃO DE COOPERAÇÃO E DESENVOLVIMENTO ECONÔMICO, 2010).

Também colabora o fato de, até os dias atuais, o Governo Estadual não ter apresentado um projeto para o ensino médio no estado, ou seja, a Secretaria de Estado de Educação (Seduc) não tem um documento orientador para a organização do trabalho pedagógico. Acabam-se restringindo a atitudes voluntaristas e de boa vontade de cada um.

A expressão "inempregáveis" explica a situação de parte da juventude paraense, sem escolaridade, com pouca escolaridade ou com escolaridade de baixa qualidade, com perspectiva de um futuro de cidadania pela metade.

A reestruturação do mundo do trabalho no âmbito da globalização da economia restringe cada vez mais o número de postos e (re)cria, na base da informalidade, ocupações precárias, que embora ainda sirvam à sobrevivência, estão longe de permitirem dignidade e cidadania a esses jovens (KUENZER, 2007).

Araujo (2007) analisa que, em pesquisa recente tratando sobre os sonhos da juventude brasileira, identificou que a maior aspiração dos jovens entre 18 e 24 anos é ter formação profissional e emprego. Na pesquisa, 55\% dos jovens entrevistados colocaram este como seu principal sonho, muito mais importante que qualquer outro desejo, como casa própria (15\%), dinheiro (9\%) ou outros.

Essa pesquisa também revela que $77 \%$ dos jovens sonham fazer curso superior, mas também indica que eles têm que conjugar suas perspectivas de trabalho com o desejo de realização pessoal. Isto remete para a ideia de que cabe à escola preparar o jovem para o mundo das profissões, mas também 
para o desenvolvimento das amplas capacidades humanas, promotoras do desenvolvimento pessoal.

Tem-se por suposto que o ensino médio é um direito de todos os jovens e que, se não garantido, coloca em risco a possibilidade de realização dos sonhos de juventude e de uma vida adulta de dignidade, considerando que, enquanto etapa de conclusão da educação básica, é nesse nível de ensino que se deve assegurar as ferramentas culturais que permitem aos jovens as habilidades comunicativas, o desenvolvimento do raciocínio lógico, os instrumentos para se situarem em seu tempo e em seu contexto social e a construção do pensamento racional-científico, em oposição ao pensamento mítico próprio da infância. Foi por isso que se convencionou, há muito tempo, que a escola é o espaço para a aprendizagem da língua materna, da matemática, da geografia e da história, bem como das ciências naturais e biológicas.

O ensino de qualidade referenciada diz respeito à assunção de uma postura pedagógica do educador em desenvolver um processo formativo em que a juventude tenha o direito a uma formação ominilateral (GRAMSCI, 1978), em oposição a formações aligeiradas. Esse compromisso parte do princípio de que os jovens, bem como toda a sociedade, devem se apropriar "[...] das ferramentas culturais necessárias à luta social que travam para se libertar das condições de exploração em que vivem" (SAVIANI, 2006, p. 71).

\section{Considerações finais}

O contexto analisado neste artigo revela tanto as particularidades como as generalidades que os fenômenos estudados representam diferentemente nos jovens ricos ou pobres. Neste sentido, há de se considerar o recorte de classe trazido a este debate, cujos impactos repercutem diferentemente sobre os sujeitos, dependendo de sua condição social.

Considerando os três ciclos econômicos importantes na região (ciclos da borracha, grande projetos e agroindústria), a vulnerabilidade socioeconômica da população lhe foi funcional nos três ciclos. Em todos prevaleceu o uso predatório da força de trabalho e o descaso com o desenvolvimento local e a valorização do homem amazônida.

Esses ciclos têm pontos em comum na intensa degradação ambiental, o uso da violência contra as populações locais, a utilização de formas precárias da força de trabalho local, o desrespeito às suas culturas e, de uma forma geral, a produção de bolsões de miséria (soldados da borracha, aglomerados urbanos próximos dos grandes projetos e remanescentes da agricultura familiar). 
As diferenças regionais são aprofundadas em função das políticas federais de distribuição de recursos e das políticas fiscais, como a Lei Kandir ${ }^{9}$.

Os dados apresentados reforçam a ideia de que "no capitalismo central e periférico a pobreza e a 'exclusão' ou inclusão precarizada jovializaram-se" (FRIGOTTO, 2004). Foi evidenciado que a juventude amazônida tem singularidades étnicas e culturais, mas também é importante mencionar que os jovens que vivem do trabalho também têm seu futuro ameaçado.

Alguns dos problemas aqui colocados requerem soluções urgentes, em particular: a morte dos jovens pela violência urbana; a baixa taxa de escolarização e a pouca qualificação da escola básica; a insegurança no mercado de trabalho; o não reconhecimento da identidade juvenil das juventudes de população tradicional; o trabalho infantil; e o trabalho escravo.

As políticas públicas devem ser dirigidas a estes fins e precisam enfrentar as consequências da dualidade estrutural. Precisam considerar a dualidade estrutural e as singularidades da juventude amazônida, em especial dos jovens em condições de vulnerabilidade social, aqui apresentadas.

Permanece válida a questão colocada por Frigotto (2004, p. 16): "Se hoje, como analisa Hobsbawm (1999), não é fácil prever quais sãos as chances de futuro digno no século 21 para as crianças e jovens dos países centrais, mais dramático é o cenário para os países do capitalismo periférico". Mais dramático ainda é o cenário das regiões periféricas dos países periféricos.

\section{Notas}

${ }^{1}$ Texto produzido em atuação junto ao Grupo de Estudos e Pesquisas sobre Trabalho e Educação da Universidade Federal do Pará (GEPTE/UFPA).

${ }^{2}$ Para a discussão da juventude amazônida, foi feito o recorte no estado do Pará.

${ }^{3}$ Considerou-se a classificação do IBGE a partir da autodeclaração como pretos e pardos na categoria "negro"; e as definições branco e amarelo na categoria "branco".

${ }^{4}$ A caracterização subnormal informa a utilização, no Brasil, de assentamentos irregulares, como favelas, invasões, palafitas etc.

${ }^{5} \mathrm{O}$ conceito de aglomerado subnormal foi utilizado pela primeira vez no Censo Demográfico de 1991. Possui certo grau de generalização, de forma 
a abarcar a diversidade de assentamentos irregulares existentes no país, conhecidos como favelas, invasões, grotas, baixadas, comunidades, vilas, ressacas, mocambos, palafitas, entre outros (IBGE, 2012).

${ }^{6} \mathrm{O}$ trabalho infantil não foi considerado como problema na Amazônia, a partir de sua inserção precoce e precária no mercado de trabalho. O Pará, por exemplo, é o estado amazônico de maior ocorrência de trabalho infantil. São cerca de 250 mil crianças e jovens entre 5 e 14 anos. No entanto, o foco deste trabalho é a juventude na idade prescrita em concordância com o IBGE.

${ }^{7}$ A "Lei Kandir", Lei Complementar Brasileira n. 87, que entrou em vigor em 13 de setembro de 1996 no Brasil, dispõe sobre o Imposto sobre Circulação de Mercadorias e Serviços (ICMS) dos estados e do Distrito Federal. A Lei Kandir isenta de ICMS os produtos e serviços destinados à exportação. Essa lei desonerou as exportações de matérias-primas e semielaborados. De acordo com técnicos do Tribunal de Contas do Estado do Pará (TCE-PA), o montante das perdas tributárias estaduais decorrentes da desoneração das exportações com base na Lei Kandir alcançou, entre 1997 e 2010, a quantia de $\mathrm{R} \$ 21,5$ bilhões (PARÁ, 2011).

\section{Referências}

ARAÚJO, Flávia Marçal Pantoja de. Notas introdutórias: a educação na Amazônia em números. In: ARAÚJO, Flávia Marçal Pantoja de. Direito humano à educação na Amazônia: uma questão de justiça. Belém, PA: Sociedade Paraense de Defesa dos Direitos Humanos, 2013.

ARAUJO, Ronaldo Marcos de Lima (Coord.). Diagnóstico dos direitos humanos no estado do Pará: (relatório final). Belém: Universidade Federal do Pará, 2007.

BRASIL. Lei n. 12.852, de 5 de agosto de 2013. Institui o Estatuto da Juventude e dispõe sobre os direitos dos jovens, os princípios e diretrizes das políticas públicas de juventude e o Sistema Nacional de Juventude - SINAJUVE. Diário Oficial da União, Brasília, DF, 2013. Disponível em: <http://www.planalto.gov.br/ccivil_03/_Ato20112014/2013/Lei/L12852.htm>. Acesso em 02 de abril 2013.

BRASIL. Ministério do Trabalho e Emprego. Agenda nacional de trabalho decente para a juventude. Brasília, DF, 2011. Disponível em: <http://www.oitbrasil.org.br/ sites/default/files/topic/employment/doc/ANTDJ.pdf>. Acesso em: 2 abr. 2017.

CARRANO, Paulo. Os múltiplos "eus" dos adolescentes: juventudes: as identidades são múltiplas: século XXI. Rio de Janeiro: Portal Multirio, 2007. Disponível em: <http://portalmultirio.rio.rj.gov.br/sec21/chave_artigo.asp?cod_artigo=1086>. Acesso em: 2 abr. 2013. 
CENTRO DE PERÍCIAS CIENTÍFICAS RENATO CHAVES. Setor Arquivo. Belém, PA, 2006. Disponível em: <http://www.cpc.pa.gov.br/>. Acesso em: 9 dez. 2012.

CERQUEIRA, Daniel et al. Atlas da violência 2016. Brasília, DF: Ipea, mar. 2016. (Nota técnica, n. 17). Disponivel em: <http://www.ipea.gov.br/portal/images/stories/ PDFs/nota_tecnica/160322_nt_17_atlas_da_violencia_2016_finalizado.pdf $>$. Acesso em: 22 dez. 2016.

CHIZZOTTI, A. Pesquisa qualitativa em ciências humanas e sociais. Petrópolis: Vozes, 2006.

CIAVATTA, Maria; RAMOS, Marise. Ensino médio e educação profissional no Brasil: dualidade e fragmentação. Retratos da Escola, Brasília, v. 5, n. 8, p. 27-41, jan./jun. 2011. Disponível em: <http://www.esforce.org.br/index.php/semestral/issue/view/10>. Acesso em: 6 fev. 2017.

CONSELHO ESTADUAL DE EDUCAÇÃO (Pará). Estudo diagnóstico sobre o ensino médio no Pará. Belém, PA, 2013. Disponível em: <http://www.cee.pa.gov.br/sites/ default/files/ESTUDO\%20SOBRE\%200\%20ENSINO\%20M\%C3\%89DI0\%20N0\%20 ESTADO\%20D0\%20PAR\%C3\%81.pdf>. Acesso em: 29 jan. 2017.

DAYRELL, J. T.; GOMES, N. L. A juventude no Brasil. Serviço Social da Indústria (SESI), n. 30, p. 25-39, dez. 1999. Disponível em: <http://www.cmjbh.com.br/arq Artigos/SESI\%20JUVENTUDE\%20NO\%20BRASIL.pdf>. Acesso em: 30 mar. 2013.

FERNANDES, R. C. Educação de jovens em situação de risco: aceleração escolar inclusiva. In: FÓRUM NACIONAL, 16., Rio de Janeiro, 2004. Economia do conhecimento, crescimento sustentado e inclusão social: painel 5. Rio de Janeiro: INAE, 2004. (Estudos e pesquisas, n. 70).

FREIRE, Jaqueline Serra. Juventude rural e políticas públicas: saberes da terra na Amazônia paraense. Tese (Doutorado) - Universidade Federal do Pará, Belém, 2007.

FRIGOTTO, Gaudêncio. Juventude, trabalho e educação no Brasil: perplexidades, desafios e perspectivas. In: NOVAES, Regina; VANNUCHI, Paulo (Org.). Juventude e sociedade: trabalho, educação, cultura e participação. São Paulo: Fundação Perseu Abramo, 2004.

\section{FUNDAÇÃO CULTURAL PALMARES. Quadro geral de Comunidades}

Remanescentes de Quilombos (CRQs). Brasília, DF, 2016. Disponível em: <http:// www.palmares.gov.br/wp-content/uploads/2016/06/QUADRO-RESUMO.pdf>. Acesso em: 8 fev. 2017.

GENTILLI, Pablo. 0 direito à educação e as dinâmicas de exclusão na América Latina.

Educação e Sociedade, Campinas, v. 30, n. 109, p. 1059-1079, set./dez. 2009.

Disponivel em: <http://www.cedes.unicamp.br>. Acesso em: 31 jan. 2017.

GRAMSCI, A. Os intelectuais e a organização da cultura. São Paulo: Civilização Brasileira, 1978.

HOBSBAWM, Eric. 0 novo século. São Paulo: Boitempo, 1999. 
IBGE. Censo 2010: aglomerados subnormais informações territoriais. Rio de Janeiro, 2010. Disponível em: <http://www.ibge.gov.br/home/presidencia/noticias/imprensa/ppt s/00000015164811202013480105748802.pdf>. Acesso em: 7 ago. 2014.

IBGE. Pesquisa nacional por amostra de domicílios, PNAD. Rio de Janeiro, 2012. Disponível em: <http://www.ibge.gov.br/home/estatistica/populacao/ trabalhoerendimento/pnad2012/default.shtm>. Acesso em: 7 fev. 2017.

INEP. Censo da educação básica 2012: resumo técnico. Brasília, DF, 2013. Disponivel em: <http://download.inep.gov.br/educacao_basica/censo_escolar/ resumos_tecnicos/resumo_tecnico_censo_educacao_basica_2012.pdf>. Acesso em: 8 fev. 2017.

INEP. IDEB: resultados e metas: 2015. Brasília, DF, 2015a. Disponível em: <http://ideb. inep.gov.br/resultado/>. Acesso em: 2 jan. 2017.

INEP. Taxas de rendimento na educação básica. Brasília, DF, 2015b. Disponível em: <http://portal.inep.gov.br/web/guest/indicadores-educacionais>. Acesso em: 30 jan. 2017.

KUENZER, Acácia. Ensino médio: construindo uma proposta para os que vivem do trabalho. 5. ed. São Paulo: Cortez, 2007.

LÜDKE, M.; ANDRÉ, M. E. D. A. Pesquisa em educação: abordagens qualitativas. São Paulo: EPU, 1986.

MUSEU do Índio, Fundação Nacional do Índio (FUNAI). Brasília, DF: Ministério da Justiça, 2010. Disponível em: <http://www.museudoindio.org.br/template_01/default. asp?ID_S=33\&ID_M=115>. Acesso em: 9 dez. 2012.

ORGANIZAÇÃO DE COOPERAÇÃO E DESENVOLVIMENTO ECONÔMICO. Panorâmica da educação: indicadores da OCDE: sumário em português. Paris, 2010. Disponível em: <http://www.oecd.org/edu/skills-beyond-school/45953903.pdf>. Acesso em: 9 ago. 2015.

OLIVEIRA, M. M. Como fazer pesquisa qualitativa. Petrópolis: Vozes, 2007.

OSORIO, Rafael Guerreiro. 0 sistema classificatório de "cor ou raça" do IBGE. Brasília, DF: Ipea, 2003. (Texto para discussão, n. 996). Disponível em: <http://www. ipea.gov.br/portal/images/stories/PDFs/TDs/td_0996.pdf>. Acesso em: 7 ago. 2015.

PARÁ. Secretaria de Justiça e Direitos Humanos do Pará. Coordenadoria de Política de Combate ao Trabalho Escravo e Tráfico de Pessoas. Belém, PA, 2015. Disponível em: <http://www.sejudh.pa.gov.br/diretorias/diretoria-de-cidadania-edireitos humanos/coordenacao-de-protecao-dos-direitos-dos-trabalhadores-rurais-e-decombate-ao-escravismo-e-trafico/>. Acesso em: 1 ago. 2015.

PARÁ. Tribunal de Contas. Lei Kandir: estudo do TCE revela que Pará já perdeu 21,5 bilhões. Belém, PA, 3 mar. 2011. Disponível em: <http://www.tce.pa.gov.br/index. php?option=com_content\&view=article\&id=676\&ltemid=58>. Acesso em: $7 \mathrm{fev}$. 2017. 
PIMENTEL, A. 0 método da análise documental: seu uso numa pesquisa histórica.

Cadernos de Pesquisa, São Paulo, n. 114, p. 179-195, nov. 2001.

SAVIANI, D. A nova lei da educação: LDB, trajetória, limites e perspectivas. 8. ed. São Paulo: Autores Associados, 2006.

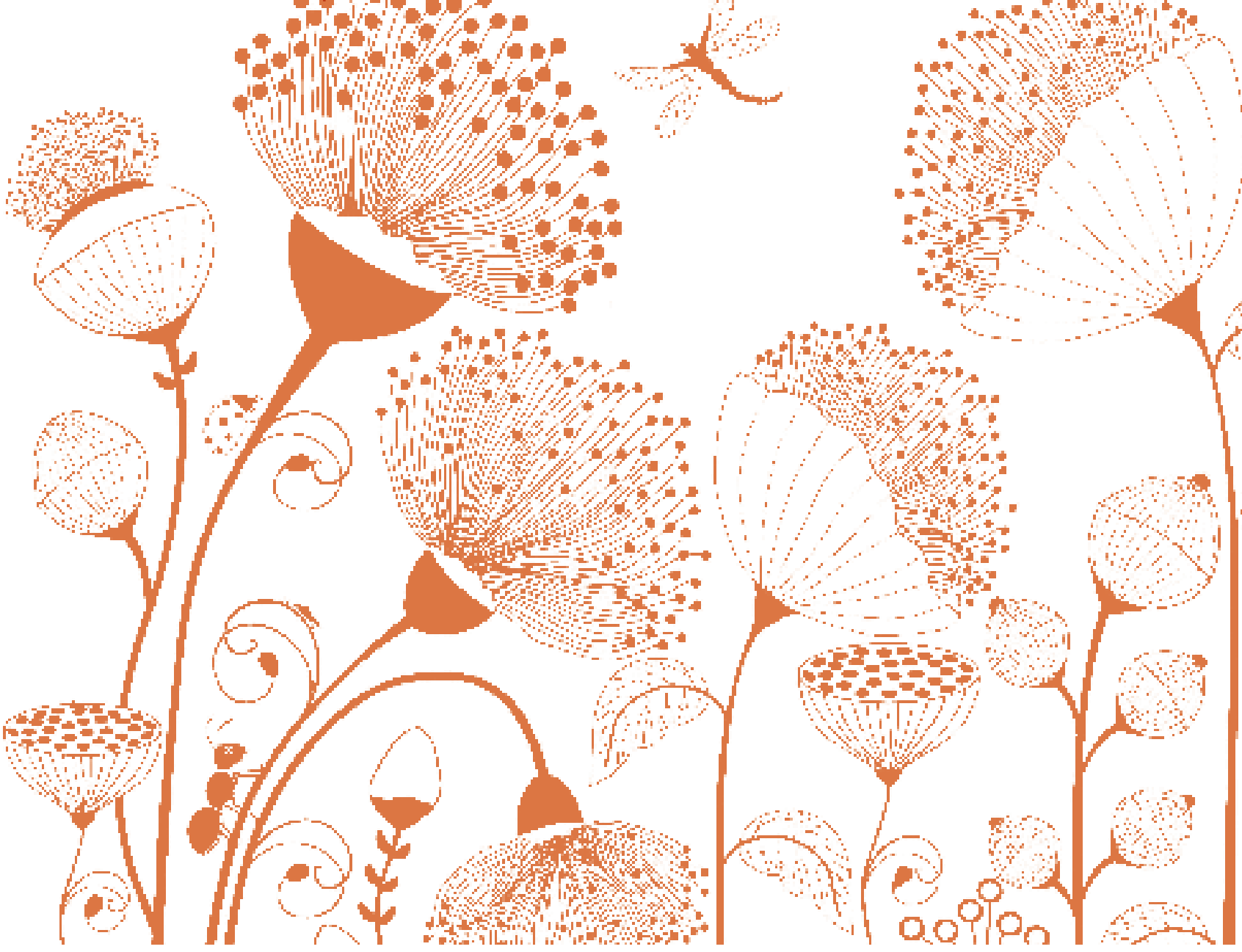

